\title{
ESTUDO MORFOLÓGICO DAS GRANULAÇÕES ARACNÓIDES HUMANAS COM REFERÊNCIA A SUA CLASSIFICAÇÃO
}

\author{
M.H. MIRANDA-NETO*, R.M.C. BRANCALHÃO**, R.P. CHOPARD***, S.L MOLINARI*
}

\begin{abstract}
RESUMO - O estudo das granulaçöes aracnóides humanas por estereomicroscópio e microscópio óptico revelou que em um mesmo indivíduo estāo presentes granulaçōes morfologicamente distintas, que classificamos em simples e lobuladas. As granulaçōes simples eram pequenas e completamente envoltas por cápsula fibrosa que delimitava, em torno das granulaçōes, espaço subdural contínuo desde o pedículo até o ápice. As granulaçōes lobuladas eram maiores que as simples; em seu ápice a cápsula era delgada e ocorria interrupçāo do espaço subdural, devido à fusāo do tecido fibroso da cápsula com a periferia da granulaçāo. As granulaçōes simples estavam possivelmente em fase inicial de desenvolvimento, enquanto as granulaçōes lobuladas estariam em fase mais avançada, com estrutura morfológica ideal para absorçāo do LCR.
\end{abstract}

PALAVRAS-CHAVE: granulaçōes aracnóides, desenvolvimento, classificaçāo.

\section{Morphological study of human arachnoid granulations with reference to their classification}

SUMMARY - Stereomicroscopic and microscopic study showed human arachnoid granulations with different morphology that we classified in simple and lobate. Simple granulations were small and completely involved by fibrous capsule that delimited a continuous subdural space from the pedicle to the apex. Lobate granulations were bigger than the simple; in the apex the fibrous capsule was thinner than in other regions, and fused with granulation periphery causing interruption of subdural space. Simple granulations might be an initial development stage; lobate granulations would represent a higher development stage, with ideal morphologic structure for absorption of the CSF.

KEY WORDS: arachnoid granulations, development, classification.

A estrutura e ultra-estrutura das granulaçōes aracnóides têm sido extensamente estudadas para elucidar a existência ou nāo de canais funcionais para a drenagem do líquido cerebrospinal (líquido cefalorraquidiano, LCR). Proposiçōes evolutivas mostram que as granulaçōes aracnóides humanas crescem e se desenvolvem com a idade ${ }^{4,5,11,20}$. Wolpow \& Schaumberg ${ }^{17}$ descrevem que as granulaçōes aracnóides humanas apresentam dois tipos morfológicos: granulaçōes pequenas revestidas por cápsula fibrosa separada do corpo da granulaçāo pelo espaço subdural e granulaçōes maiores, onde existem regiōes em que o corpo da granulação se projeta através da dura-máter.

Kida et al. ${ }^{8}$ e Yamashima ${ }^{18-19}$ revelam que, na porçāo apical, as granulaçōes aracnóides nāo se apresentam envoltas pela cápsula fibrosa nem pelas células endoteliais. Neste caso, 0 espaço subdural perde sua continuidade e as células aracnóides ficam em contato com a luz do seio sagital superior. Por outro lado, outros autores afirmam que a granulaçáo aracnóide é totalmente revestida,

Estudo realizado em cooperação entre os Departamentos de Ciências Morfofisiológicas da Universidade Estadual de Maringá (UEM) e de Anatomia do Instituto de Ciências Biomédicas da Universidade de São Paulo (ICB - USP): * Professor Adjunto e Professora Assistente do Departamento de Ciências Morfofisiológicas da UEM; ** Professora Assistente do Departamento de Ciências Biológicas e Fisíco-Químicas da UNEOESTE; *** Professor Assistente Doutor do Departamento de Anatomia do ICB-USP. Aceite: 29-julho-1993.

Dr. Marcílio Hubner de Miranda Neto - Universidade Estadual de Maringá - Av. Colombo 3690 Bloco H-79 Sala 07 - 87020-900 Maringá PR - Brasil. 
havendo, portanto, um espaço subdural em torno delas ${ }^{1-3,6,7,9,12-14}$. A existência dessas controvérsias nos motivou a realizar estudo meso e microscópico das granulaçōes aracnóides humanas, buscando desta forma contribuir com informaçōes referentes a sua morfologia.

\section{MATERIAL E MÉTODO}

O material consistiu de 20 peças anatômicas obtidas de cadáveres de adultos de ambos os sexos, com idade variando entre 20 e 40 anos. As peças retiradas foram fixadas em formalina a $10 \%$ por 96 horas; a seguir este material foi reduzido a pequenas amostras com aproximadamente $1 \mathrm{~cm}$, contendo o seio sagital superior e as estruturas adjacentes. Trinta amostras do material foram dissecadas e analisadas sob estereomicroscópio. A seguir, 15 destas amostras foram submetidas ao processo de elaboração de preparados totais pelo método de Van Gieson segundo Otto e 15 à metodologia histológica de rotina para inclusāo em parafina e realizaçāo de cortes de 20 micrómetros, corados pelos métodos de Azan e deWeigert. Os preparados totais foram fotografados com auxílio de estereomicroscópio Zeiss, enquanto os cortes selecionados para documentação foram fotografados em fotomicroscópio Wild M.20.

\section{RESULTADOS}

As observaçōes sob estereomicroscópio revelaram a presença de granulaçōes aracnóides caracterizadas por dimensōes e formas diversas, perfurando o folheto interno da dura-máter e projetando-se na luz do seio sagital superior (Figura 1). Nas regiōes em que estavam presentes as granulaçōes, como ocorre no assoalho do seio sagital superior (Figura 2B), a dura-máter apresentava-se dissociada em feixes de espessuras e direçóes várias, cruzando-se em planos diferentes, formando malhas que deixavam espaços irregulares predominantemente losângicos por onde penetravam os pedículos das granulaçōes. Em direta continuidade com os feixes da dura-máter, observou-se delgada membrana que se descreveu como cápsula fibrosa. Esta interpōe-se entre o seio sagital superior e a granulaçāo, acompanhando a granulaçāo desde a regiāo pedicular até o ápice; entre esta cápsula e a granulaçăo notou-se delicada fenda correspondente ao espaço subdural (Figura 2A).

Nas granulaçōes aracnóides menores, a cápsula era constituída de tecido conjuntivo denso e delimitava o espaço subdural, contínuo desde o pedículo até o ápice da granulaçāo (Figura 2A).

Na regiāo apical das granulaçōes maiores ocorriam interrup̧̧ōes do espaço subdural, devidas à uniāo dos feixes colágenos da periferia da granulaçāo com os da cápsula fibrosa. Nesses locais, os feixes de colágenos da cápsula dissociavam-se bruscamente e, com aspecto ondulado, espraiavam-se sobre a periferia da granulaçāo, formando redes frouxas e delicadas (Figura 4A).

Os feixes de fibras elásticas acompanhavam a disposição descrita para os feixes colágenos; nas regiōes de interrupçāo do espaço subdural as fibras elásticas organizavam-se em feixes concêntricos que se uniam aos feixes elásticos da cápsula fibrosa (Figura 4B).

Com base nessas características, reunimos as granulaçōes aracnóides em dois grupos:

A. SIMPLES: Em geral menores e arrendondadas, revestidas por cápsula fibrosa contínua desde o pedículo até o ápice: entre a cápsula fibrosa c a peri feria da granulaçāo nota-sc o espaço subdural ininterrupto (Figuras 1 e 2A).

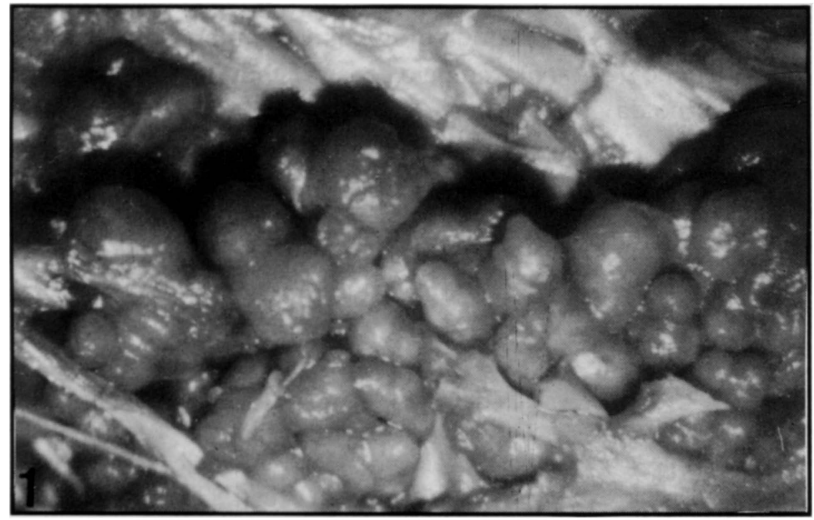

Figura 1. Fotografia do seio sagital superior mostrando aglomerados de granulaçōes aracnóides, de dimensões e morfologia diferentes, em seu assoalho, sobre o folheto interno da dura-máter (x 20).
B. LOBULADAS: São as maiores granulaçōes, podendo apresentar nas suas superfícies sulcos únicos ou múltiplos, de direçōes diferentes, determinando aspectos bi ou plurilobulados. Esta disposiçäo em boceladuras nos permitiu distinguir lóbulos irregulares menores e maiores (Figuras 1 e 3). No ápice desses lóbulos observou-se adelgaçamento da cápsula fibrosa, com interrupçāo do espaço subdural e fusão dos elementos fibrosos da cápsula com a periferia da granulaçāo (Figuras 3 e 4). 


\section{COMENTÁRIOS}

O entrecruzamento dos feixes da dura-máter já foi anteriormente estudado ${ }^{10}$. Contudo, a disposição que descrevemos, em traves de espessura e comprimento variáveis orientadas em direçōes diversas e anastomosadas em planos diferentes, sugere que estes espaços não tenham dimensōes estáticas e que, pelo fato de estarem dispostos em torno dos pedículos das granulaçōes, poderiam agir sobre eles contribuindo na regulaçāo do fluxo do LCR através das granulaçōes.

A existência da cápsula

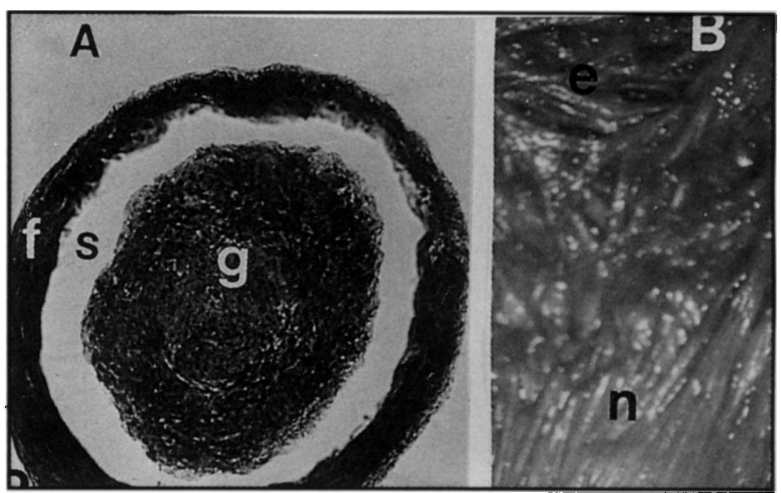

Figura 2. Em A, corte transversal de 20 micrômetros corado por Azan, evidenciando o centro de uma granulação $(g)$, espaço subdural $(s) e$ cápsula fibrosa $(f)(x$ 100). Em B, preparado de Van Gieson mostrando o entrecruzamento dos feixes da dura-máter em regiäo onde havia granulações (e), diferente de $(n)$ onde não existiam granulaçöes $(x 8)$. fibrosa refletindo-se da dura-máter e delimitando o espaço subdural é referida pela maioria dos autores que estudaram as granulaçōes aracnóides em humanos ${ }^{10,17-20}$. Kida et al. ${ }^{8}$ nāo admitem a existência do espaço subdural devido à fusāo da cápsula fibrosa $\infty \mathrm{m}$ a periferia da granulaçāo; provavelmente seus estudos assentaram-se sobre granulaçōes lobuladas em regiōes de interrupçāo do espaço subdural.

Devido à morfologia distinta das granulaçöes e ao comportamento diferencial da cápsula

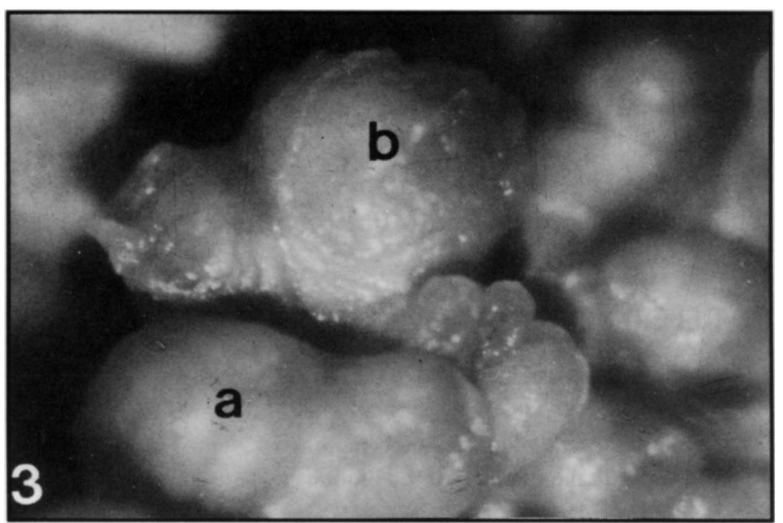

Figura 3. Fotografia do seio supeior, com vista superior de uma granulação aracnóide bilobulada (a) totalmente revestida pela cápsula fibrosa e uma granulação aracnóide plurilobulada (b) sem o revestimento capsular no ápice $(x 30,2)$. fibrosa, preferimos classificá-las segundo o aspecto e dimensōes em: SIMPLES, menores e revestidas por cápsula fibrosa e espaço subdural contínuo; LOBULADAS, maiores, podendo haver a interrupção do espaço subdural na regiảo apical devido à fusāo da cápsula fibrosa com a periferia da granulação. Assim, as granulaçōes ficam melhor caracterizadas, fato não apontado pelos autores consultados; apenas Wolpow \& Schaumberg ${ }^{17}$ as denominaram pequenas e maiores.

As diferentes formas de granulaçōes encontradas podem relacionar-se a estágios de desenvolvimento. Granulaçēes simples, sugerem estágio inicial de desenvolvimento. Quando as granulaçōes começam a se desenvolver provocam afastamento dos feixes da dura-máter. Neste processo dinâmico, a dura-máter sofreria herniaçāo em direçāo ao seio sagital superior e originaria a cápsula fibrosa. À medida que as granulaçōes vão se tornando maiores, seu ápice entraria em íntimo contato com a cápsula fibrosa, fundindo-se a esta. Estes aspectos sāo concordes com proposiçōes evolutivas ${ }^{17,20}$.

As granulaçöes lobuladas estariam em estágios funcionais mais adiantados. $O$ adelgaçamento e a fusāo da cápsula fibrosa com a periferia da granulaçāo, com consequente interrupçāo do espaço subdural na 


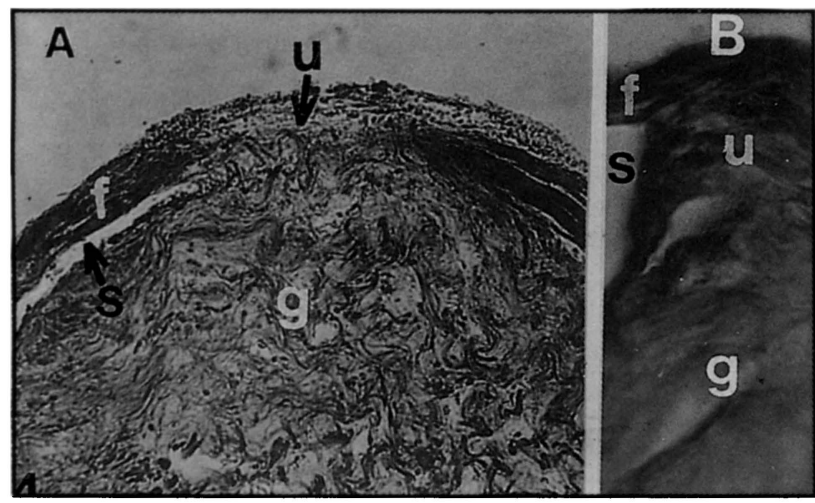

Figura 4. Em A, corte transversal de 20 micrômetros, corado por Azan, evidenciando a uniäo $(u)$ dos feixes de fibras colágenas de granulação $(g)$ com os feixes da cápsula fibrosa (f);espaço subdural (s) (x 400). Em B, corte transversal de 20 micrômetros corado por Weigert evidenciando a união $(u)$ dos feixes de fibras elásticas da granulação $(g)$ com os feixes da cápsula fibrosa (f); espaço subdural (s) (x 400).

regiāo apical, representariam o estágio ideal para absorçāo do LCR, devido a redução na espessura da barreira mecânica que este deve atravessar para alcançar os seios da duramáter. Talvez essas diferenças morfológicas nas granulaçōes aracnóides sejam responsáveis pelas contradiçōes encontradas na literatura. É possível que os autores que afirmam serem as granulaçōes aracnóides totalmente revestidas pela cápsula, delimitando espaço subdural contínuo, tenham assentado suas observaçōes em granulaçōes aracnóides simples ${ }^{1-3,6,7,9,12-15}$. Por outro lado, os autores que afirmam ser o espaço subdural interrompido na regiāo apical, provavelmente estudaram granulaçōes aracnóides lobuladas ${ }^{8,19} 16-20$.

Em vista do exposto acreditamos que, para se estudar as granulaçöes aracnóides, deve-se considerar o estágio do desenvolvimento em que se encontram.

\section{CONCLUSÕES}

1. Em material de um mesmo indivíduo podem ser encontradas granulaçōes aracnóides em diferentes estágios de desenvolvimento. 2. As granualçōes SIMPLES (menores) sāo completamente envoltas pela cápsula fibrosa e espaço subdural contínuo. 3. Nas granulaçōes LOBULADAS (maiores), a cápsula fibrosa da regiāo apical funde-se com a periferia da granulaçāo, ocorrendo a interrupçāo do espaço subdural nesta regiāo. 4. Para se estudar as granulaçōes aracnóides, deve-se levar em consideração suas diferenças morfológicas (quando SIMPLES ou LOBULADAS) e a regiāo estudada (pedículo, centro ou ápice).

\section{REFERÊNCIAS}

1. Alksne JF, White LEJ. Electron-microscope study of the effect of increased intracranial pressure on the arachnoid villus. J Neurosurg 1965, 22:481-488.

2. Alksne JF, Richamond VA. Arachnoid villi after subarachnoid blood. J Neuropathol Exp Neurol 1971, 30:135.

3. Alksne JF, Lovings ET. The role of the arachnoid villus in the removal of red blood cells from the subarachnoid space: an electron microscope study in the dog. J Neurosurg 1972, 36:192-200.

4. Clark LC. On the pacchionian bodies. J Anat 1920, 55:40-48.

5. Cunningham DJ. Anatomia humana Ed. 8 Barcelona: Manuel Marin 1949, T II.

6. Ellington E, Margolis G. Block of arachnoid villus by subarachnoid hemmorhage.J Neurosurg 1969, 30:651-657.

7. Jullow J, Ishii M, Iwabuchi T. Arachnoid villi affected by subarachnoid pressure and hemorrhage: scanning electron microscopicstudy in the dog. Acta Neurchir 1979, 51:63-72.

8. Kida S, Yamashima T, Kubota T, Ito H, Yamamoto S. A light and electron microscopic and immunohistochemical study of human arachnoid villi. J Neurosurg 1988, 69:429-435.

9. Lee BCP, Gomez DG, Potts DG, Pavese AM. Passage of amipaque (metrizamide) through the arachnoid granulations. Neuroradiology 1979, 17:185-190.

10. Miranda-Neto MH, Biazotto W, Chopard RP, Lucas GA. Estudo micro-mesoscópico das granulaçōes aracnóides humanas. Arq Neuro-Psiquiatr 1990, 48:151-155.

11. Paturet G. Traité d'anatomie. Paris:Masson 1964, T IV.

12. Shabo AL, Maxwell DS. The morphology of the arachnoid villi: a light and electron microscopic study in the monkey. J Neurosurg 1968, 29:451-463. 
13. Shabo AL, Maxwell DS. Electron microscopic observations on the fate of particulate matter in the cerebrospinal fluid. J Neurosurg 1968, 29:464-474.

14. Shabo AL, Abbott MM, Maxwell DS. The response of the arachnoid villus to an intracisternal injection of autogenous brain tissue: an electron study in the macaque monkey. J Neurosurg 1969, 19:724-734.

15. Tripathi $R$. Tracing the bulk outflow route of cerebrospinal fluid by transmission and scanning electron microscopy. Brain Res 1974, 80:503-506.

16. Upton ML, Weller RO, Path FRC. The morphology of cerebrospinal fluid drainage pathways in human arachnoid granulations. J Neurosurg 1985, 63:867-875.

17. Wolpow ER, Schaumberg HH. Structure of the human arachnoid granulation. J Neurosurg 1972, 37:724-727. 18. Yamashima $T$. Uttrastructural study of the final cerebrospinal fluid pathway in human arachnoid villi. Brain Res 1986, 384:68-76.

19. Yamashima T. Functional ultrastructure of cerebrospinal fluid drainage channels in human arachnoid villi. Neurosurgery 1988, 22:633-641.

20. Zakiw. Dévélopment des granulations arachnoidennes. Bull Assoc Anat 1977, 161:283-290. 